\title{
Hyperoxia improves repeated-sprint ability and the associated training load in athletes
}

\author{
Shannon Cyr-Kirk ${ }^{1}$, François Billaut ${ }^{1} *$ \\ ${ }^{1}$ Département de kinésiologie, Université Laval, Québec, QC, Canada
}

* Correspondence:

Prof François Billaut

francois.billaut@kin.ulaval.ca

\section{Abstract}

This study investigated the impact of hyperoxic gas breathing (HYP) on repeated-sprint ability (RSA) and on the associated training load (TL). Thirteen team- and racquet-sport athletes performed 6-s all-out sprints with 24-s recovery until exhaustion (power decrement $\geq 15 \%$ for two consecutive sprints) under normoxic (NOR: $\mathrm{F}_{\mathrm{I}} \mathrm{O}_{2}$ 0.21) and hyperoxic ( $\mathrm{HYP}: \mathrm{F}_{\mathrm{i}} \mathrm{O}_{2}$ 0.40) conditions in a randomized, single-blind and crossover design. The following variables were recorded throughout the tests: mechanical indices, arterial $\mathrm{O}_{2}$ saturation $\left(\mathrm{S}_{\mathrm{p}} \mathrm{O}_{2}\right)$, oxygenation of the vastus lateralis muscle with near-infrared spectroscopy, and electromyographic activity of the vastus lateralis, rectus femoris and gastrocnemius lateralis muscles. Session TL (work $\mathrm{x}$ rate of perceived exertion) and neuromuscular efficiency (work/EMG) were calculated. Compared with NOR, HYP increased $\mathrm{S}_{\mathrm{p}} \mathrm{O}_{2}$ $(2.7 \pm 0.8 \%$, Cohen's effect size ES 0.55$)$, the number of sprints $(14.5 \pm 8.6 \%$, ES 0.28$)$, the total mechanical work $(13.6 \pm 6.8 \%$, ES 0.30) and the session TL (19.4 $\pm 7.0 \%$, ES 0.33). Concomitantly, HYP increased the amplitude of muscle oxygenation changes during sprints $(25.2 \pm 11.7 \%$, ES 0.36$)$ and recovery periods $(26.1 \pm 11.4 \%$, ES 0.37$)$, as well as muscle recruitment $(9.9 \pm 12.1 \%$, ES 0.74$)$ and neuromuscular efficiency $(6.9 \pm 9.0 \%, \mathrm{ES} 0.24)$. We conclude that breathing a hyperoxic mixture enriched to $40 \% \mathrm{O}_{2}$ improves the total work performed and the associated training load during an open-loop RSA session in trained athletes. This ergogenic impact may be mediated by metabolic and neuromuscular alterations.

Keywords: hyperoxia, oxygen supplementation, training load, multiple sprints, team sports, muscle oxygenation.

\section{Introduction}

The nature and the magnitude of a training effect are dictated by the frequency, duration and intensity of the exercise, the so-called training load (TL). Those parameters are modulated multiple times during a training cycle to manage fatigue accumulation and ensure progressive, specific physiological adaptations. Enhancement in athletic performance is well known to be attributable to the controlled fluctuation of the TL throughout the year (Busso, Denis, Bonnefoy, Geyssant, \& Lacour, 1997; FitzClarke, Morton, \& Banister, 1991). Therefore, the understanding and quantification of the impact of varied stimuli on TL represent a key element to sport performance optimization (Foster et al., 2001). 
Among the multiple stimuli used by athletes and coaches to increase TL and promote physiological adaptations, oxygen supplementation (i.e., hyperoxia) appears very attractive due to nearly all physiological functions relying on this gas. With growing popularity since its approbation by the World Anti-Doping Agency (WADA) in 2001, hyperoxia can be obtained by increasing the inspired oxygen fraction $\left(\mathrm{F}_{\mathrm{I}} \mathrm{O}_{2}\right.$, normobaric hyperoxia) and/or the barometric pressure (hyperbaric hyperoxia). Performance during aerobic exercise such as time trials, time to exhaustion, graded exercise tests and dynamic muscle function tests is, not surprisingly, acutely improved under hyperoxic conditions(Adams \& Welch, 1980; Amann et al., 2006; Peltonen et al., 1997; Richardson et al., 1999). Those improvements are mainly derived from the increase in arterial hemoglobin saturation $\left(\mathrm{S}_{\mathrm{a}} \mathrm{O}_{2}\right)$, arterial content of oxygen $\left(\mathrm{C}_{\mathrm{a}} \mathrm{O}_{2}\right)$ and, therefore, the systemic $\mathrm{O}_{2}$ delivery to organs and skeletal muscles (Peltonen et al., 1995; Powers, Martin, \& Dodd, 1993), which attenuate exerciseinduced hypoxemia (Nummela, Hämäläinen, \& Rusko, 2002) and alter energy metabolism (Linossier, Dormois, Arsac, Denis, \& Lacour, 2000). Hyperoxia has also been used during repeated high-intensity exercise and results are promising. Higher peak and mean power output have been documented when breathing $100 \% \mathrm{O}_{2}$, compared to room air, during two 30-s cycle sprints separated by $4 \mathrm{~min}$ (Kay, Stannard, \& Morton, 2008), during five sets of 40 high-intensity breast strokes ( $\sim 50$ s) (Sperlich et al., 2011), and during ten 15-s cycling sprints interspersed with 45 s of recovery (Porter, Reed, \& Jones, 2020). Overall, these data indicate that hyperoxia may be beneficial to exercise performance in varied sport settings, although the activity patterns of intermittent sports such as rackets and team sports have received limited attention so far.

During most team and racket sports, athletes repeat brief maximal or near-maximal efforts (i.e., sprints, changes of direction, jumps) with short recoveries at low to moderate intensity, throughout the duration of the competition. This physical quality, called repeated-sprint ability (RSA), is critical to success, and coaches and support staff use different training methods to enhance RSA during training (Billaut \& Bishop, 2009; Bishop, Girard, \& Mendez-Villanueva, 2011; Girard, MendezVillanueva, \& Bishop, 2011). Many metabolic (e.g. phosphocreatine resynthesis, aerobic and anaerobic glycolysis, metabolite accumulation) and neuromuscular factors (e.g. muscle activation strategies) determine RSA, which have been reviewed in details elsewhere (Billaut \& Bishop, 2009; Bishop et al., 2011; Girard et al., 2011). While the short maximal efforts rely heavily on anaerobic metabolic systems to produce ATP as rapidly as possible during the first sprints, early research using muscle biopsy has also well demonstrated that when sprints are repeated with brief and incomplete recovery, the contribution of the anaerobic glycolysis to ATP resynthesis diminishes and the aerobic metabolism becomes more critical (Gaitanos, Williams, Boobis, \& Brooks, 1993). This is confirmed by studies using hypoxia to reduce tissue oxygen availability. For example, Billaut et al. demonstrated with near-infrared spectroscopy (NIRS) that reducing arterial $\mathrm{O}_{2}$ saturation led to a decline in muscle oxygenation which impaired RSA in trained athletes (Billaut \& Buchheit, 2013). Furthermore, the recovery of performance between sprints is purely fueled via aerobic energy sources, and muscle tissue reoxygenation has been shown to be another determinant of RSA (Billaut \& Buchheit, 2013; Buchheit \& Ufland, 2011). With such metabolic changes occurring during a repeated-sprint training session, one may expect a hyperoxic mixture to enhance some the aerobic components of RSA and, thereby, better maintain performance. A higher exercise intensity or the possibility to perform more sprint repetitions during a given training session would lead to a higher TL, and theoretically, greater training adaptations over time. However, to our best knowledge, no study has assessed the influence of HYP on RSA and the associated TL.

Before promoting such practice in training, one may first assess the efficacy of adding hyperoxia to a repeated-sprint training session with athletes. Therefore, we examined the effects of acute normobaric hyperoxia on RSA, key psycho-physiological parameters and TL in trained athletes. We 
hypothesized that hyperoxia would enhance muscle reoxygenation and better maintain muscle recruitment, which would lead to enhanced RSA and TL.

\section{$3 \quad$ Materials and methods}

\subsection{Ethics approval}

The study was approved by the Ethics Committee of University Laval, and adhered to the principles established in the Declaration of Helsinki. Participants provided written informed consent after being informed of experimental procedures, associated risks and potential benefits.

\subsection{Participants}

Thirteen athletes (including 5 women) volunteered for this study (mean \pm SE; age, $23.0 \pm 2.7 \mathrm{yr}$; body mass, $70.7 \pm 14.9 \mathrm{~kg}$; stature, $175.5 \pm 7.3 \mathrm{~cm}$; percent body fat, $14.00 \pm 4.38 \%$ ). All participants were non-smokers, free of health problems, and did not use any medication or any other tobacco/nicotine products. Participants were training 8 (range 6-12) hour per week (in a sport that included high-intensity short intervals (e.g., basketball, hockey and badminton). They avoided vigorous exercise, drug and nutritional supplements $48 \mathrm{~h}$ before test and refrained from alcohol and caffeine for $12 \mathrm{~h}$. They were also asked to consume a regular meal at least $2 \mathrm{~h}$ before every session and to keep a constant training load during the course of the study.

\subsection{Experimental design}

Participants visited the laboratory for one preliminary visit and two experimental trials during which all testing procedures were performed by the same investigator. Sessions were separated by a minimum of 2 days to avoid fatigue and a maximum of 7 days.

During the first visit, stature, body mass and percentage body fat (Tanita TBF-310; Tanita Corp. of America Inc., Arlington Heights, IL) were recorded. Resting heart rate and blood pressure (inclusion criteria, $<140 / 100 \mathrm{~mm} \mathrm{Hg}$ ) were taken before trial in a seated position. The handlebars and seat were adjusted vertically and horizontally to each participants preference, and feet were secured to the pedals using toe clips. These settings were also replicated for all subsequent trials. Participants completed a 10-min standardized, specific RSA warm-up on a computer-controlled electrically braked cycle ergometer (Velotron Elite; RacerMate, Seattle, WA). After 3 min of passive rest, they performed a force-velocity (FV) test to determine the optimal cycling resistance (see Force-Velocity Test procedures below). Athletes had $5 \mathrm{~min}$ of passive recovery and were then familiarized with the RSA test procedures. They executed a shortened version of the RSA test (see Repeated-Sprint Ability Test procedures below) which included six 6-s sprints while wearing the breathing mask only.

Following the preliminary visit, athletes were randomised in a single-blind, cross-over design and asked to perform a RSA test in normoxia (NOR, $\mathrm{F}_{\mathrm{I}} \mathrm{O}_{2}$ 0.21) and in normobaric hyperoxia $\left(\mathrm{HYP}, \mathrm{F}_{\mathrm{I}} \mathrm{O}_{2}\right.$ 0.40). Normoxic and hyperoxic gas mixtures were delivered by a continuous-flow $\mathrm{O}_{2}$ concentrator (New Life Intensity 10, AirSep Corporation, Buffalo, NY) and administered via a rig of 3 x 170-liter Douglas bags connected to a facemask (AltitudeTech Inc, Kingston, ON, Canada). After the standardized warm-up, participants were instrumented with the NIRS device, electromyography electrodes and pulse oximeter. For both experimental trials, the breathing apparatus was installed one minute before the beginning of the RSA test and was removed after the last sprint. A 5-minute cooldown was observed after every trial. 


\section{$123 \quad 3.4 \quad$ Testing procedures}

\section{$124 \quad 3.4 .1$ Standardized warm-up}

125 A standardised warm-up was realized by the athletes before the force-velocity and the RSA tests. It 126 included a total of $3 \mathrm{~min}$ of moderate intensity cycling, two $15 \mathrm{~s}$ accelerations with $15 \mathrm{~s}$ active 127 recovery, $1 \mathrm{~min} 30 \mathrm{~s}$ of moderate intensity and then three $6 \mathrm{~s}$ sprints at $80 \%, 90 \%$ and $100 \%$ of their 128 maximal effort with $24 \mathrm{~s}$ of recovery between each of them. The last three minutes of the warm-up were passive rest where they could stay on the bike without pedaling or stand-up.

\section{$130 \quad 3.4 .2$ Force-Velocity Test}

131 Athletes performed five maximal 6-s cycle sprints against increasing resistances and interspersed 132 with 4 min of passive recovery. Sprints were initiated with 5-s of cycling at a standardized cadence 133 (between 80-90 rpm) with the same resistance of the following sprint. Athletes were allowed to stand-up for the first two pedal strokes and then remained seated for the duration of the sprint and were strongly encouraged to reach maximal power output as quickly as possible (same instructions were given for the RSA test). The individual power-velocity relationships were obtained, and the optimal cycling resistance was defined as the gear for which maximal cycling power output was reached.

\subsubsection{Repeated-Sprint Ability Test}

After the standardised warm-up, participants performed consecutive maximal 6-s cycle sprints, separated by $24 \mathrm{sec}$ of rest (19 $\mathrm{sec}$ of passive rest and $5 \mathrm{sec}$ of progressive re-acceleration of the flywheel) until exhaustion on an electronically braked cycle ergometer (Velotron Elite, RacerMate, Seattle, WA). An electronic tablet with a visual and audible signal was placed directly in front of the participants for precise count-down. Participants were asked to stop pedalling immediately at the end of the sprint. The resistance determined during the force-velocity test was set at the beginning of the RSA test and did not change afterwards. Following the test, all instrumentation was removed, and participants performed a self-paced cool down of at least 3 minutes.

To reduce the inter-subject variability in performance decrement and to enable a more standardized level of fatigue between the participants, both RSA tests were stopped when participants completed two consecutive sprints with a percent decrement score $\left(S_{D E C}\right)$ higher than $15 \%$ or if they reached 20 sprints (Morin, Dupuy, \& Samozino, 2011). The $\mathrm{S}_{\mathrm{DEC}}$ across the sprints was determined as the percent difference between total and ideal performance (Glaister, Howatson, Pattison, \& McInnes, 2008), as follows: $S_{\mathrm{DEC}}=(100 \mathrm{x}$ (total performance $/$ ideal performance $\left.)\right)-100$, where total performance is the sum of the PPO from all sprints performed, and ideal performance is the highest PPO recorded multiplied by the number of sprints performed.

The Velotron ergometer provides instantaneous, average and peak values for power output, pedal frequency and speed at $23 \mathrm{~Hz}$. The mechanical work $(\mathrm{kJ})$ performed during every sprint was calculated by integrating the instantaneous power curve over the $6 \mathrm{sec}$ of the sprint. The number of sprints, the peak power output (PPO) and the total mechanical work ( $\mathrm{W}_{\text {tot }}$, the sum of the work from all sprints) were measured and calculated. We also calculated the sum of the mechanical work values for the common sprints (i.e., the sprints performed by every participant in the two conditions, $\mathrm{W}_{\text {com }}$ ).

162 For example, if a participant performed 12 sprints in NOR and 14 sprints in HYP, only the first 12 sprints of each condition were taken for the $\mathrm{W}_{\text {com }}$ calculation. 


\subsection{Exercise physiological responses}

165

166

167

168

169

170

171

172

173

174

175

176

177

\subsubsection{Rate of perceived exhaustion (RPE)}

Perceived exhaustion $\left(\mathrm{RPE}_{\mathrm{tot}}\right)$, perceived limb discomfort $\left(\mathrm{RPE}_{\text {lim }}\right)$ and perceived difficulty breathing $\left(\mathrm{RPE}_{\text {bre }}\right)$ were recorded from a modified Borg CR10 scale after every sprint. Participants were asked to point the number associated with their perceived effort on a printed scale. The session rating of perceived exertion (sRPE) was also calculated and considered as the main variable to measure TL (Foster et al., 2001). Calculation: $\mathrm{sRPE}=\left(\mathrm{W}_{\text {tot }} \mathrm{X}\right.$ average rates of perceived effort $)$.

\subsubsection{Arterial $\mathrm{O}_{2}$ saturation $\left(\mathrm{S}_{\mathrm{p}} \mathrm{O}_{2}\right)$ and heart rate $(\mathrm{HR})$}

$\mathrm{S}_{\mathrm{p}} \mathrm{O}_{2}$ was estimated via pulse oximetry (Nellcor Bedside; Nellcor Inc. Hayward, CA) with adhesive optodes placed on the forehead. The reproducibility and validity (intraclass correlation coefficient $=$ 0.99) for this method of measurement for saturations above $80 \%$ has been shown to be in good agreement with hemoglobin $\mathrm{O}_{2}$ when compared with arterial blood gas measurements (Romer et al., 2007). The $\mathrm{S}_{\mathrm{p}} \mathrm{O}_{2}$ and the $\mathrm{HR}$ were recorded at rest, and immediately after every sprint and every recovery period. The lowest value of $\mathrm{S}_{\mathrm{p}} \mathrm{O}_{2}$ recorded during the RSA test was considered as $\mathrm{S}_{\mathrm{p}} \mathrm{O}_{2 \mathrm{~min}}$.

\subsubsection{Near-infrared spectroscopy (NIRS)}

A portable spatially-resolved, dual wavelength NIRS apparatus (PortaMon, Artinis Medical Systems BV, The Netherlands) was installed on the distal part of the right vastus lateralis muscle belly (approximately $15 \mathrm{~cm}$ above the proximal border of the patella), parallel to muscle fibers, to quantify changes in the absorption of near-infrared light by oxyhemoglobin/myoglobin $\left(\mathrm{O}_{2} \mathrm{Hb} / \mathrm{Mb}\right)$ and deoxyhemoglobin/myoglobin $(\mathrm{HHb} / \mathrm{Mb})$. Skinfold thickness was measured at the site of the application of the NIRS $(9.0 \pm 4.6 \mathrm{~mm})$ using a Harpenden skinfold caliper (British Indicators Ltd, West Sussex, Great Britain) during the familiarization session and was less than half the distance between the emitter and the detector (i.e., $20 \mathrm{~mm}$ ). This thickness is adequate to let near-infrared light through muscle tissue (McCully \& Hamaoka, 2000). The device was packed in transparent plastic wrap to protect it from sweat and fixed with tape. Black bandages were used to cover the device from interfering background light. The position of the apparatus was marked with an indelible pen for repositioning in the subsequent visit.

A modified form of the Beer-Lambert law, using two continuous wavelengths (760 and $850 \mathrm{~nm})$ and a differential optical path length factor of 4.95, was used to calculate micromolar concentrations in tissue $\mathrm{O}_{2} \mathrm{Hb} / \mathrm{Mb}, \mathrm{HHb} / \mathrm{Mb}$ and total hemoglobin/myoglobin $\left([\mathrm{THb} / \mathrm{Mb}]=\left[\mathrm{O}_{2} \mathrm{Hb} / \mathrm{Mb}\right]+[\mathrm{HHb} / \mathrm{Mb}]\right.$ ). The tissue saturation index $\left(\mathrm{TSI}=\left[\mathrm{O}_{2} \mathrm{Hb} / \mathrm{Mb}\right] /[\mathrm{THb} / \mathrm{Mb}]\right)$ was also calculated. Exercise data was normalised to a 1-min baseline recorded before the warm-up of visit 2 and 3 (defined as $0 \mu \mathrm{M}$ ). The NIRS data were acquired continuously at $10 \mathrm{~Hz}$ and then filtered using a tenth-order Butterworth low-pass filter with a $4 \mathrm{~Hz}$ cut-off frequency. Analysis of muscle oxygenation was limited to $[\mathrm{HHb} / \mathrm{Mb}]$ because this variable is less sensitive than $\left[\mathrm{O}_{2} \mathrm{Hb} / \mathrm{Mb}\right]$ to perfusion variations during contraction and recovery and is closely related to the venous $\mathrm{O}_{2}$ content (De Blasi, Cope, Elwell, Safoue, \& Ferrari, 1993; Ferrari, Mottola, \& Quaresima, 2004), and to TSI because this parameter is independent of near-infrared photon path length in tissue and reflects the dynamic balance between $\mathrm{O}_{2}$ supply and $\mathrm{O}_{2}$ consumption in the microcirculation (Van Beekvelt, Colier, Wevers, \& Van Engelen, 2001). From the filtered signal, the maximal and minimal [HHb/Mb], [THb/Mb] and TSI were identified for every sprint/recovery cycle from a 5-sec moving average to identify the maximal upper and lower limits of the signals (Rodriguez, Townsend, Aughey, \& Billaut, 2018). We further calculated the deoxygenation amplitude during sprints $\left(\Delta[\mathrm{HHb} / \mathrm{Mb}]_{\text {exercise }}\right.$ and $\left.\Delta \mathrm{TSI} \mathrm{I}_{\text {exercise }}\right)$ as the 
average difference between maximal and minimal $[\mathrm{HHb} / \mathrm{Mb}]$ and TSI values for every sprint. Similarly, the reoxygenation amplitude during post-sprint recovery periods $\left(\Delta[\mathrm{HHb} / \mathrm{Mb}]_{\text {recovery }}\right.$ and $\left.\Delta \mathrm{TSI}_{\text {recovery}}\right)$ was calculated as the difference between maximal and minimal $[\mathrm{HHb} / \mathrm{Mb}]$ and $\mathrm{TSI}$ values for every recovery period.

Normalized NIRS values were also represented as percentage of RSA test completion. As the fewer number of sprints realized by a participant was five, we divided data series in five segments to obtain beginning (0\%), 25\%, 50\%, $75 \%$ and $100 \%$ of sprint completion, and calculated the averages of all parameters for every segment.

\section{$215 \quad 3.5 .4$ Electromyography (EMG)}

The EMG signals of the vastus lateralis, rectus femoris and gastrocnemius lateralis were recorded from the dominant lower limb via surface electrodes (Delsys, Trigno Wireless, Boston, MA) during every sprint. A careful preparation of the skin (shaving, light abrasion and cleaning with an alcohol swab) on the electrodes sites was made before every test. Electrodes were fixed longitudinally (aligned parallel to the underlying muscle fibre direction) over the muscle belly. The EMG signal was pre-amplified and filtered (bandwidth $12-500 \mathrm{~Hz}$, gain $=1,000$, sampling frequency $2 \mathrm{kHz}$ ) and recorded with Delsys hardware (Bagnoli EMG System; Delsys, Inc., USA). During postprocessing, the onset and offset of activation of all EMG bursts in all muscles and every sprint were detected manually. The activity of each muscle was determined by calculating the integral of the EMG (iEMG) and the median power frequency (MPF) between the onset and the offset of the last 6 subsequent bursts of the sprint. Values of iEMG of every muscle were summed together and a new sum-iEMG parameter was used to represent the global muscle activity during sprints (Billaut et al., 2013; Billaut, Physiology, Nutrition, and, 2009; Smith \& Billaut, 2010). The sum-iEMG for all the sprints (sum-iEMG $\mathrm{tot}_{\text {to }}$ ) and for the common sprints (sum-iEMG $\mathrm{Com}_{\mathrm{co}}$ ) were also calculated.

Neuromuscular efficiency (NME) was calculated for every sprint as the ratio of work to sum-iEMG $\left(\mathrm{NME}=\right.$ work/sum-iEMG) and expressed for all the sprints $\left(\mathrm{NME}_{\mathrm{tot}}\right)$ and for the common sprints $\left(\mathrm{NME}_{\mathrm{com}}\right)$. A decrease in NME would indicate perturbations in muscle contractility (Bigland-Ritchie, 1981). Mechanical and EMG parameters are reported as raw data and as percent of the first sprint value. Normalisation has been used widely when the effects of fatigue on force production and EMG activity are studied (Bigland-Ritchie, 1981; Hunter, Critchlow, Shin, \& Enoka, 2004).

\section{$236 \quad 3.6 \quad$ Statistical Analysis}

All data are reported as means $\pm \mathrm{SD}$, percentage of normalized values or percentage of change from NOR. The NOR and HYP differences were analysed using Cohen's effect size (ES) $\pm 90 \%$ confidence limits and compared to the smallest worthwhile change (0.2 multiplied by the betweenparticipant SD) (Batterham \& Hopkins, 2005; Hopkins, Marshall, Batterham, \& Hanin, 2009). Effect sizes were classified as small $(>0.2)$, moderate $(>0.5)$ and large $(>0.8)$, and only likely effects (>75\%) are reported (Batterham \& Hopkins, 2005; Hopkins et al., 2009).

\section{Results}

\section{$244 \quad 4.1 \quad$ Mechanical and perceptual measurements}

245 Performance variables are presented in Table 1 and Figure 1. The PPO reached was similar in both 246 conditions, but HYP extended the number of sprints performed before exhaustion compared to NOR 
(difference between groups $14.5 \pm 8.6 \%$, ES 0.28). The total work performed over the entire series also increased in HYP $(13.6 \pm 6.8 \%$, ES 0.30), but when the same number of sprints was considered in both NOR and HYP, the work in these common sprints did not change meaningfully $(2.0 \pm 1.7 \%$, ES 0.05). Similar effects were observed when analyzing work to body mass ratio $(\mathrm{J} / \mathrm{kg})$ on $\mathrm{W}_{\text {tot }}(13.6$ $\pm 6.8 \%$, ES 0.27) and $\mathrm{W}_{\text {com }}(2.0 \pm 1.7 \%$, ES 0.04).

Importantly, HYP also increased the session TL by $19.4 \pm 7.0 \%$ (ES 0.33). HYP also increased $\operatorname{RPE}_{\text {tot }}(8.9 \pm 5.9 \%$, ES 0.47$)$ and $\mathrm{RPE}_{\text {bre }}(7.5 \pm 7.3 \%$, ES 0.40). There was no clear difference between conditions for RPE $\mathrm{lim}_{\text {. }}$

\subsection{Arterial oxygenation and heart rate}

Breathing the hyperoxic mixture increased the averaged $\mathrm{S}_{\mathrm{p}} \mathrm{O}_{2}$ recorded during the entire series of sprints $(2.7 \pm 0.8$, ES 0.55$)$ as well as the lowest $\mathrm{S}_{\mathrm{p}} \mathrm{O}_{2}$ (HYP $99.2 \pm 0.8$ vs NOR $95.1 \pm 2.1$, difference $4.4 \pm 1.0$, ES 1.85). Furthermore, HR was lower in HYP (HYP $163.1 \pm 14.2$ bpm vs NOR $164.8 \pm$ $12.6 \mathrm{bpm}$, difference $-1.1 \pm 1.9$, ES -0.24).

\subsection{Muscle oxygenation}

263

Figure 2 displays the changes in NIRS variables over the RSA test in both NOR and HYP. During the sprints, the maximal metabolic alterations $\left([\mathrm{HHb} / \mathrm{Mb}]_{\max }\right.$ and $\mathrm{TSI}_{\min }$ ) were not different between conditions, however we observed greater average muscle deoxygenation amplitude when sprints were performed in HYP compared with NOR $\left(\Delta[\mathrm{HHb} / \mathrm{Mb}]_{\text {exercise }}: 25.2 \pm 11.7 \%\right.$, ES 0.36 and $\Delta \mathrm{TSI}_{\text {exercise }}: 14.0 \pm 13.3 \%$, ES 0.62).

The metabolic status of the recovery periods between sprints was also altered by the condition. Muscle reoxygenation was greater in $\mathrm{HYP}\left(\Delta[\mathrm{HHb} / \mathrm{Mb}]_{\text {recovery }}: 26.1 \pm 11.4 \%, \mathrm{ES} 0.37\right.$ and $\Delta \mathrm{TSI}_{\text {recovery }}: 27.8 \pm 15.7 \%$, ES 0.53$)$. This led to lower values of $[\mathrm{HHb} / \mathrm{Mb}]_{\min }$ in $\mathrm{HYP}$ at the beginning ( $-3.5 \pm 4.1 \%$, ES -0.25$), 25 \%(-3.5 \pm 5.2 \%$, ES -0.24$), 50 \%(-3.2 \pm 5.1 \%, \mathrm{ES}-0.22)$ and $75 \%(-3.0 \pm 5.5 \%$, ES -0.21$)$ of test completion. Furthermore, TSI $\mathrm{max}_{\max }$ was higher in HYP at the beginning (7.0 $\pm 6.7 \%$, ES 0.36), 25\% (7.0 $\pm 6.9 \%$, ES 0.36), 50\% (5.8 $\pm 7.8 \%$, ES 0.30), $75 \%$ (5.9 \pm $7.8 \%$, ES 0.31$)$ and $100 \%(6.3 \pm 7.9 \%$, ES 0.33$)$ of test completion. An increase in $[\mathrm{THb} / \mathrm{Mb}]_{\max }$ was also observed at the beginning $(4.3 \pm 4.7 \%$, ES 0.45), $25 \%(3.3 \pm 3.9 \%$, ES 0.35$), 50 \%(2.7 \pm 3.5 \%$, ES 0.29), $75 \%(2.1 \pm 3.4 \%$, ES 0.22) and $100 \%(1.9 \pm 3.5 \%$, ES 0.21).

\subsection{Electromyographic activity}

278

279

280

281

282

283

284

285

HYP increased sum-iEMG tot $_{\text {by }} 9.9 \pm 12.1 \%$ (ES 0.74) and sum-iEMG com $_{\text {by }} 10.2 \pm 12.0 \%$ (ES 0.77). When looking at muscles individually, HYP increased the average value of the vastus lateralis sum$\mathrm{iEMG}_{\text {tot }}$ by $10.3 \% \pm 11.8 \%$ (ES 0.71 ) and that of the rectus femoris sum-iEMG $\mathrm{tot}_{\text {to }}$ by $14.8 \% \pm 16.7 \%$ (ES 0.93), while no change was observed in the gastrocnemius lateralis.

NME values are presented in Figure 3. Mean value of $\mathrm{NME}_{\text {tot }}$ increased in HYP $(6.9 \pm 9.0 \%$, ES $0.24)$ as well as mean value of $\mathrm{NME}_{\text {com }}(7.8 \pm 8.7 \%$, ES 0.27). Finally, MPF decreased from $82.3 \pm$ $13.9 \mathrm{~Hz}$ to $77.85 \pm 10.81 \mathrm{~Hz}$ in NOR and from $81.75 \pm 13.22$ to $78.14 \pm 10.61 \mathrm{~Hz}$ in HYP, without showing any clear difference between conditions. 


\section{Discussion}

288

289

290

291

292

293

The present study was performed to assess the acute effects of breathing a hyperoxic mixture on psycho-physiological responses and performance during a repeated-sprint ability test in athletes. The main results were that hyperoxia enhanced sprint endurance during short cycling sprints and the training load of the session. This improvement in mechanical performance may have been due to the concomitant increase in muscle oxygenation fluxes during sprints and recovery periods subsequent to the enhancement in arterial $\mathrm{O}_{2}$ saturation and in neuromuscular recruitment.

\subsection{Hyperoxia and repeated-sprint session training load}

The present study demonstrated that the initial sprint mechanical indices (work and PPO) were not altered by HYP. This comes with no surprise since the ability to produce maximal power during short efforts is mainly derived from anaerobic energy sources (Calbet, De Paz, Garatachea, de Vaca, \& Chavarren, 2003). This is in keeping with the robust finding that lowering $\mathrm{F}_{\mathrm{I}} \mathrm{O}_{2}$ (i.e., hypoxia) also does not impair maximal power output (Balsom, Ekblom, \& Sjödin, 1994; Billaut \& Buchheit, 2013; Smith \& Billaut, 2010). Taken together, this data suggests that short-term maximal performance is well preserved in face of a wide range of $\mathrm{F}_{\mathrm{I}} \mathrm{O}_{2}$. The initial sprint performance is related to the mechanical decrement occurring in subsequent sprints (Bishop, Lawrence, \& Spencer, 2003), thus we can exclude the influence of this methodological factor on RSA in the present study. When sprints are repeated, the accumulation of metabolic end-products linked to high rates of anaerobic glycolysis induces muscle fatigue. In this regard, breathing more $\mathrm{O}_{2}$ may attenuate the loss of power and prolong exercise. Indeed, participants produced $\sim 14 \%$ more work over the entire series in HYP compared to room air, and this enhanced performance likely came from a greater aerobic ATP production (Calbet, Martín-Rodríguez, Martin-Rincon, \& Morales-Alamo, 2020). Such ergogenic effect has also been reported during sprints of 15 to 30 -s duration with $100 \% \mathrm{O}_{2}$ (Kay et al., 2008; Porter et al., 2019). Our data therefore adds to the literature that mild hyperoxia $\left(40 \% \mathrm{O}_{2}\right)$ can also enhance RSA during very short efforts.

In addition to the greater performance, HYP exacerbated the breathing and total effort perception. Overall, HYP increased the session TL by $\sim 19 \%$, and this occurred in 12 participants out of 13 . A further interesting result, with practical applications for training, was that HYP enhanced performance by increasing the number of repetitions without altering the work performed during the sprints that were common to both conditions. This represents a differing ergogenic impact of hyperoxia during short vs long sprints, in which power output appears to increase during the sprint (Kay et al., 2008; Porter et al., 2020). This is likely caused by the different muscle energetics during efforts of varying duration (Calbet et al., 2020). Since aerobic processes become more predominant as 6-s sprints are repeated (Gaitanos et al., 1993), it is not surprising to observe the ergogenic impact of hyperoxia in the latter stages of a RSA protocol. This difference may also be caused by the mild hyperoxia used in the present study compared with a $1.0 \mathrm{~F}_{\mathrm{I}} \mathrm{O}_{2}$ in former studies. Nonetheless, for the coach or sport scientist aiming to increase TL during RSA sessions with team- and racquet-sport athletes, it may be more relevant to use open-loop exercises in which athletes can perform more repetitions before ending a session. Such training approach will have to be tested in long-term, periodizsed, longitudinal studies.

\subsection{Hyperoxia and arterial and muscle oxygenation}


Although hypoxemia is rarely seen during RSA protocols at sea level, it may still develop during longer exercise protocols and hinder performance (Billaut \& Smith, 2010). Considering the criteria defined by Dempsey and Wagner (Dempsey \& Wagner, 1999), our results show that seven participants experienced mild hypoxemia $\left(>3 \% \mathrm{~S}_{\mathrm{p}} \mathrm{O}_{2}\right.$ fall from resting levels) and one participant experienced moderate hypoxemia $\left(\mathrm{S}_{\mathrm{p}} \mathrm{O}_{2}<93 \%\right)$ during the test. Oxygen availability is generally accepted to play an important role during RSA tests. In fact, arterial hypoxemia imposed by hypoxia induces greater metabolic perturbations and reduces performance during repeated sprints with brief recovery (Balsom, Ekblom, \& Sjödin, 1994; Smith \& Billaut, 2010; 2012). Here, HYP had a clear positive impact to prevent the fall in $\mathrm{S}_{\mathrm{p}} \mathrm{O}_{2}$ and maintained it at $99-100 \%$ throughout the test. Interestingly, the five athletes displaying no significant fall in $\mathrm{S}_{\mathrm{p}} \mathrm{O}_{2}$ in NOR were those exhibiting the smallest difference in mechanical work between NOR and HYP.

To our best knowledge, the present study is the first to report changes in muscle oxygenation during repeated sprints under hyperoxia. The performance gains in HYP were concomitant with greater muscle oxygenation fluxes. Typically, muscle deoxygenation increases rapidly in the first sprint and then plateaus in the subsequent sprints, which indicates maximal skeletal muscle $\mathrm{O}_{2}$ extraction early in the exercise (Billaut \& Buchheit, 2013; Buchheit \& Ufland, 2011; Buchheit et al., 2009; Smith \& Billaut, 2010). HYP could not enhance this mechanism further since both $[\mathrm{HHb} / \mathrm{Mb}]_{\max }$ and $\mathrm{TSI}_{\min }$ remained similar to those observed in NOR. However, $\Delta[\mathrm{HHb} / \mathrm{Mb}]_{\text {exercise }}$ and $\Delta \mathrm{TSI}_{\text {exercise }}$ increased in HYP, indicative of greater peripheral muscle $\mathrm{O}_{2}$ extraction when more $\mathrm{O}_{2}$ is available before reaching maximal limit. Thus, one may argue that the relative contribution of the oxidative metabolism vs anaerobic glycolysis was greater during the sprints in HYP, thereby contributing to prolong exercise.

This greater aerobic contribution during exercise was probably possible through changes in the recovery. The lower $[\mathrm{HHb} / \mathrm{Mb}]_{\min }$ and greater $\mathrm{TSI}_{\max }, \Delta[\mathrm{HHb} / \mathrm{Mb}]_{\text {recovery }}$ and $\Delta \mathrm{TSI}_{\text {recovery }}$ suggest that HYP also enhanced oxygenation status of the muscle during recovery periods. Muscular activity is dependent on the balance between $\mathrm{O}_{2}$ delivery and $\mathrm{O}_{2}$ consumption by the skeletal muscle fibers, and convective delivery of $\mathrm{O}_{2}$ is regulated by blood flow supplying the working muscles and the $\mathrm{O}_{2}$ content of the blood. HYP enhanced $\mathrm{S}_{\mathrm{p}} \mathrm{O}_{2}$ and also $[\mathrm{THb} / \mathrm{Mb}]_{\max }$ suggesting a greater regional volume of $\mathrm{O}_{2}$-rich blood. Although we could not measure blood flow per se, it is still likely that $\mathrm{O}_{2}$ delivery and utilisation were enhanced during the recovery between sprints. Muscle reoxygenation plays a critical role on RSA (Billaut \& Buchheit, 2013; Buchheit et al., 2009). The present results confirm these findings and together highlight muscle reoxygenation capacity as an important factor of the ability to reproduce mechanical performance in subsequent sprint repetitions. The recovery of phosphocreatine and muscle reoxygenation after exercise presents similar kinetics (Chance, Dait, Zhang, Hamaoka, \& Hagerman, 1992; Kime et al., 2003; McCully et al., 1994), and it has been reported that hyperoxia accelerates phosphocreatine resynthesis (Haseler, Richardson, Videen, \& Hogan, 1998; Hogan, Richardson, \& Haseler, 1999). It is therefore probable that a better muscle reoxygenation in HYP would have translated into a better $\mathrm{PCr}$ resynthesis during the recovery periods and a higher $\mathrm{PCr}$ availability for subsequent sprints.

Although the maximal peripheral $\mathrm{O}_{2}$ uptake during the sprints did not appear to differ between the environments, probably due to the very high intensity of the efforts and stress put on the oxidative pathway, HYP still generated marked amplitudes of tissue oxygenation during both sprint and recovery. Repeated fluctuations of tissue partial pressure of $\mathrm{O}_{2}$ are necessary for muscular oxidative capacity adaptations (Casey \& Joyner, 2012; Daussin et al., 2008). Thus, in addition to increasing a session TL, hyperoxia may also be an effective environmental stress for inducing peripheral adaptations by imposing repeated muscle oxygenation fluxes. 


\subsection{Hyperoxia and muscle recruitment}

375 Under substantial fatigue (evaluated at $>10 \%$ fatigue index or sprint decrement), a concomitant attenuation of EMG activity and mechanical performance is usually observed across sprint repetitions (Billaut \& Buchheit, 2013; Mendez-Villanueva, Hamer, \& Bishop, 2008; Mendez-Villanueva, 2007; Racinais et al., 2007). This suggests that the ability to fully activate the working muscles may be incriminated in the loss of mechanical output. Motor neuron activity is greatly influenced by $\mathrm{O}_{2}$ availability (Amann, Romer, Subudhi, Pegelow, \& Dempsey, 2007; Bigland-Ritchie, Dawson, Johansson, \& Lippold, 1986; Szubski, Burtscher, \& Löscher, 2006). In the RSA literature, the reduction in $\mathrm{S}_{\mathrm{p}} \mathrm{O}_{2}$ has been correlated with the attenuation in surface EMG activity (Billaut \& Smith, 2010), and has also been shown to accentuate the decline in central motor command assessed from peripheral muscle stimulation (Billaut et al., 2013). Our results therefore suggest that $\mathrm{O}_{2}$ supplementation during sprints helps maintain a higher muscle recruitment (as evidenced by a $\sim 10 \%$ higher sum-iEMG indices in HYP). The most likely explanation would be that the greater tissue perfusion and oxygenation improved the metabolic milieu of contracting muscles and attenuated the reflex inhibition originating from group III and IV afferents, thereby maintaining neural drive to skeletal muscles (Amann \& Dempsey, 2008).

There is also the possibility that changes in EMG indices related at least in part to sarcolemma excitability and changes in conduction velocity of action potentials. Membrane excitability is impaired during intense fatiguing exercise as a result of a lower activity of the sodium $\left(\mathrm{Na}^{+}\right) /$potassium $\left(\mathrm{K}^{+}\right)$-adenosine triphosphatase (NKA) activity to maintain transmembrane ionic gradient caused by the decline in $\mathrm{pH}$ and accumulation of inorganic phosphates. Greater muscle perfusion and oxygenation during sprints could have altered energy metabolism and the subsequent accumulation of by-products and acidosis that resulted in lesser sarcolemma dysfunction (Linossier et al., 2000). Future studies should more robustly investigate the potential attenuation of centrally mediated decline in neural drive and alterations in M-wave amplitude.

\section{Conclusion}

401

This study demonstrated that breathing a hyperoxic mixture with $40 \% \mathrm{O}_{2}$ improved the total work performed and the associated training load during an open-loop test of RSA in trained team- and racquet-sport athletes. This ergogenic effect occurred concurrent with an increase in muscle oxygenation fluxes during sprints and recovery periods and in neuromuscular recruitment. Although this study showed promising results about the effectiveness of mild hyperoxia to enhance TL during RSA sessions, important factors such as manipulation of $\mathrm{F}_{\mathrm{I}} \mathrm{O}_{2}$ and optimum exercise-to-rest ratios remain to be explored for efficient applications.

\section{$407 \quad 7 \quad$ Author Contributions}

SCK and FB conceptualized and designed the research project; SCK acquired the data and conducted the statistical analysis; SCK interpreted results with assistance from FB; SCK wrote the manuscript with revisions from FB; all authors reviewed and agreed upon the final manuscript.

\section{Acknowledgments}

412 The authors thank the athletes for their participation in this study. We also sincerely thank all

413 graduate and undergraduate students from our research group for their valuable help, as well as TMC

414 distribution for the generous loan of the oxygen concentrator. 


\section{Conflict of Interest}

416 The authors declare that the research was conducted in the absence of any commercial or financial

417 relationships that could be construed as a potential conflict of interest.

\section{$418 \quad 10 \quad$ References}

419

420

421

422

423

424

425

426

427

428

429

430

431

432

433

434

435

436

437

438

439

440

441

442

443

444

445

446

447

448

449

450

451

452

453

454

455

456

457

458

459

Adams, R. P., \& Welch, H. G. (1980). Oxygen uptake, acid-base status, and performance with varied inspired oxygen fractions. Journal of Applied Physiology, 49(5), 863-868. http://doi.org/10.1152/jappl.1980.49.5.863

Amann, M., \& Dempsey, J. A. (2008). Locomotor muscle fatigue modifies central motor drive in healthy humans and imposes a limitation to exercise performance. The Journal of Physiology, 586(1), 161-173. http://doi.org/10.1113/jphysiol.2007.141838

Amann, M., Eldridge, M. W., Lovering, A. T., Stickland, M. K., Pegelow, D. F., \& Dempsey, J. A. (2006). Arterial oxygenation influences central motor output and exercise performance via effects on peripheral locomotor muscle fatigue in humans. The Journal of Physiology, 575(3), 937-952. http://doi.org/10.1113/jphysiol.2006.113936

Amann, M., Romer, L. M., Subudhi, A. W., Pegelow, D. F., \& Dempsey, J. A. (2007). Severity of arterial hypoxaemia affects the relative contributions of peripheral muscle fatigue to exercise performance in healthy humans. The Journal of Physiology, 581(1), 389-403. http://doi.org/10.1113/jphysiol.2007.129700

Balsom, P. D., Ekblom, B., \& Sjödin, B. (1994a). Enhanced oxygen availability during high intensity intermittent exercise decreases anaerobic metabolite concentrations in blood. Acta Physiologica Scandinavica, 150(4), 455-456. http://doi.org/10.1111/j.1748-1716

Batterham, A. M., \& Hopkins, W. G. (2005). Making meaningful inferences about magnitudes. Sportscience, 9, 6-14.

Bigland-Ritchie, B. (1981). Emg/Force relations and fatigue of human voluntary contractions. Exercise and Sport Sciences Reviews, 9(1), 75.

Bigland-Ritchie, B. R., Dawson, N. J., Johansson, R. S., \& Lippold, O. C. (1986). Reflex origin for the slowing of motoneurone firing rates in fatigue of human voluntary contractions. The Journal of Physiology, 379(1), 451-459. http://doi.org/10.1113/jphysiol

Billaut, F., \& Bishop, D. (2009). Muscle fatigue in males and females during multiple-sprint exercise. Sports Medicine (Auckland, N.Z.), 39(4), 257-278. http://doi.org/10.2165/00007256200939040-00001

Billaut, F., \& Buchheit, M. (2013). Repeated-sprint performance and vastus lateralis oxygenation: effect of limited O $\square$ availability. Scandinavian Journal of Medicine \& Science in Sports, 23(3), e185-93. http://doi.org/10.1111/sms.12052

Billaut, F., \& Smith, K. (2010). Prolonged Repeated-Sprint Ability Is Related to Arterial O2 Desaturation in Men. International Journal of Sports Physiology and Performance, 5(2), $197-$ 209. http://doi.org/10.1123/ijspp.5.2.197

Billaut, F., Kerris, J. P., Rodriguez, R. F., Martin, D. T., Gore, C. J., \& Bishop, D. J. (2013). Interaction of central and peripheral factors during repeated sprints at different levels of arterial O2 saturation. PloS One, 8(10), e77297. http://doi.org/10.1371/journal.pone.0077297

Billaut, F., \& Smith, K. (2009). Sex alters impact of repeated bouts of sprint exercise on neuromuscular activity in trained athletes. NRC Research Press. http://doi.org/doi:10.1139/H09058

Bishop, D., Girard, O., \& Mendez-Villanueva, A. (2011). Repeated-Sprint Ability - Part II. Sports Medicine (Auckland, N.Z.), 41(9), 741-756. http://doi.org/10.2165/11590560-000000000-00000 
Bishop, D., Lawrence, S., \& Spencer, M. (2003). Predictors of repeated-sprint ability in elite female hockey players. Journal of Science and Medicine in Sport, 6(2), 199-209. http://doi.org/10.1016/s1440-2440(03)80255-4

Buchheit, M., \& Ufland, P. (2011). Effect of endurance training on performance and muscle reoxygenation rate during repeated-sprint running. European Journal of Applied Physiology, 111(2), 293-301. http://doi.org/10.1007/s00421-010-1654-9

Buchheit, M., Cormie, P., Abbiss, C. R., Ahmaidi, S., Nosaka, K. K., \& Laursen, P. B. (2009). Muscle deoxygenation during repeated sprint running: Effect of active vs. passive recovery. International Journal of Sports Medicine, 30(6), 418-425. http://doi.org/10.1055/s-00281105933

Busso, T., Denis, C., Bonnefoy, R., Geyssant, A., \& Lacour, J.-R. (1997). Modeling of adaptations to physical training by using a recursive least squares algorithm. Journal of Applied Physiology, 82(5), 1685-1693. http://doi.org/10.1152/jappl.1997.82.5.1685

Calbet, J. A. L., De Paz, J. A., Garatachea, N., de Vaca, S. C., \& Chavarren, J. (2003). Anaerobic energy provision does not limit Wingate exercise performance in endurance-trained cyclists. Journal of Applied Physiology. http://doi.org/10.1152/japplphysiol.00128.2002

Calbet, J. A. L., Martín-Rodríguez, S., Martin-Rincon, M., \& Morales-Alamo, D. (2020). An integrative approach to the regulation of mitochondrial respiration during exercise: Focus on high-intensity exercise. Redox Biology, 35, 101478. http://doi.org/10.1016/j.redox.2020.101478

Casey, D. P., \& Joyner, M. J. (2012). Compensatory vasodilatation during hypoxic exercise: mechanisms responsible for matching oxygen supply to demand. The Journal of Physiology, 590(24), 6321-6326. http://doi.org/10.1113/jphysiol.2012.242396

Chance, B., Dait, M. T., Zhang, C., Hamaoka, T., \& Hagerman, F. (1992). Recovery from exerciseinduced desaturation in the quadriceps muscles of elite competitive rowers. The American Journal of Physiology, 262(3 Pt 1), C766-75. http://doi.org/10.1152/ajpcell.1992.262.3.C766

Daussin, F. N., Zoll, J., Ponsot, E., Dufour, S. P., Doutreleau, S., Lonsdorfer, E., et al. (2008). Training at high exercise intensity promotes qualitative adaptations of mitochondrial function in human skeletal muscle. Journal of Applied Physiology (Bethesda, Md. : 1985), 104(5), 14361441. http://doi.org/10.1152/japplphysiol.01135.2007

De Blasi, R. A., Cope, M., Elwell, C., Safoue, F., \& Ferrari, M. (1993). Noninvasive measurement of human forearm oxygen consumption by near infrared spectroscopy. European Journal of Applied Physiology, 67(1), 20-25. http://doi.org/10.1007/BF00377698

Dempsey, J. A., \& Wagner, P. D. (1999). Exercise-induced arterial hypoxemia. Journal of Applied Physiology, 87(6), 1997-2006. http://doi.org/10.1152/jappl.1999.87.6.1997

Ferrari, M., Mottola, L., \& Quaresima, V. (2004). Principles, Techniques, and Limitations of Near Infrared Spectroscopy. Canadian Journal of Applied Physiology, 29(4), 463-487. http://doi.org/10.1139/h04-031

Fitz-Clarke, J. R., Morton, R. H., \& Banister, E. W. (1991). Optimizing athletic performance by influence curves. Journal of Applied Physiology, 71(3), 1151-1158. http://doi.org/10.1152/jappl.1991.71.3.1151

Foster, C. G., Florhaug, J. A., Franklin, J. E., Gottschall, L., Hrovatin, L. A., Parker, S., et al. (2001). A new approach to monitoring exercise training. The Journal of Strength and Conditioning Research, 15(1), 109. http://doi.org/10.1519/1533-4287

Gaitanos, G. C., Williams, C., Boobis, L. H., \& Brooks, S. (1993). Human muscle metabolism during intermittent maximal exercise. Journal of Applied Physiology (Bethesda, Md. : 1985), 75(2), 712-719. http://doi.org/10.1152/jappl.1993.75.2.712

Girard, O., Mendez-Villanueva, A., \& Bishop, D. (2011). Repeated-Sprint Ability - Part I. Sports Medicine (Auckland, N.Z.), 41(8), 673-694. http://doi.org/10.2165/11590550-000000000-00000 
508

509

510

511

512

513

514

515

516

517

518

519

520

521

522

523

524

525

526

527

528

529

530

531

532

533

534

535

536

537

538

539

540

541

542

543

544

545

546

547

548

549

550

551

552

553

554

555

Glaister, M., Howatson, G., Pattison, J. R., \& McInnes, G. (2008). The Reliability and Validity of Fatigue Measures During Multiple-Sprint Work: An Issue Revisited. The Journal of Strength \& Conditioning Research, 22(5), 1597-1601. http://doi.org/10.1519/JSC.0b013e318181ab80

Haseler, L. J., Richardson, R. S., Videen, J. S., \& Hogan, M. C. (1998). Phosphocreatine hydrolysis during submaximal exercise: the effect of F I O 2. Journal of Applied Physiology. http://doi.org/10.1152/jappl.1998.85.4.1457

Hogan, M. C., Richardson, R. S., \& Haseler, L. J. (1999). Human muscle performance and PCr hydrolysis with varied inspired oxygen fractions: a 31P-MRS study. Journal of Applied Physiology (Bethesda, Md. : 1985), 86(4), 1367-1373. http://doi.org/10.1152/jappl.1999.86.4.1367

Hopkins, W. G., Marshall, S. W., Batterham, A. M., \& Hanin, J. (2009). Progressive Statistics for Studies in Sports Medicine and Exercise Science. Medicine and Science in Sports and Exercise, 4l(1), 3-13. http://doi.org/10.1249/MSS.0b013e31818cb278

Hunter, S. K., Critchlow, A., Shin, I.-S., \& Enoka, R. M. (2004). Men are more fatigable than strength-matched women when performing intermittent submaximal contractions. Journal of Applied Physiology, 96(6), 2125-2132. http://doi.org/10.1152/japplphysiol.01342.2003

Kay, B., Stannard, S. R., \& Morton, R. H. (2008). Hyperoxia during recovery improves peak power during repeated wingate cycle performance. Brazilian Journal of Biomotrocity, 41, 92-100.

Kime, R., Karlsen, T., Nioka, S., Lech, G., Madsen, Ø., Sæterdal, R., et al. (2003). Discrepancy between cardiorespiratory system and skeletal muscle in elite cyclists after hypoxic training. Dynamic Medicine, 2(1), 1-9. http://doi.org/10.1186/1476-5918-2-4

Linossier, M. T., Dormois, D., Arsac, L., Denis, C., \& Lacour, J. R. (2000). Effect of hyperoxia on aerobic and anaerobic performances and muscle metabolism during maximal cycling exercise. Acta Physiologica Scandinavica, 168(3), 403-11. http://doi.org/10.1046/j.1365201x.2000.00648.x

McCully, K. K., \& Hamaoka, T. (2000). Near-infrared spectroscopy: what can it tell us about oxygen saturation in skeletal muscle? Exercise and Sport Sciences Reviews, 28(3), 123-127.

McCully, K. K., Iotti, S., Kendrick, K., Wang, Z., Posner, J. D., Leigh, J., \& Chance, B. (1994). Simultaneous in vivo measurements of $\mathrm{HbO} 2$ saturation and $\mathrm{PCr}$ kinetics after exercise in normal humans. Journal of Applied Physiology (Bethesda, Md. : 1985), 77(1), 5-10. http://doi.org/10.1152/jappl.1994.77.1.5

Mendez-Villanueva, A., Hamer, P., \& Bishop, D. (2007). Fatigue Responses During Repeated Sprints Matched for Initial Mechanical Output. American College of Sports Medicine. http://doi.org/10.1249/mss.0b013e31815669dc

Mendez-Villanueva, A., Hamer, P., \& Bishop, D. (2008). Fatigue in repeated-sprint exercise is related to muscle power factors and reduced neuromuscular activity. European Journal of Applied Physiology, 103(4), 411-419. http://doi.org/10.1007/s00421-008-0723-9

Morin, J.-B., Dupuy, J., \& Samozino, P. (2011). Performance and fatigue during repeated sprints: what is the appropriate sprint dose? Journal of Strength and Conditioning Research, 25(7), 1918-1924. http://doi.org/10.1519/JSC.0b013e3181e075a3

Nummela, A., Hämäläinen, I., \& Rusko, H. (2002). Effect of hyperoxia on metabolic responses and recovery in intermittent exercise. Scandinavian Journal of Medicine \& Science in Sports, 12(5), 309-315. http://doi.org/10.1034/j.1600-0838.2002.10157.x

Peltonen, J. E., Rantamäki, J., Niittymäki, S. P., Sweins, K., Viitasalo, J. T., \& Rusko, H. K. (1995). Effects of oxygen fraction in inspired air on rowing performance. Medicine and Science in Sports and Exercise, 27(4), 573-579. http://doi.org/10.1007/s40279-017-0791-2

Peltonen, J. E., Rusko, H. K., Rantamäki, J., Sweins, K., Niittymäki, S., \& Viitasalo, J. T. (1997). Effects of oxygen fraction in inspired air on force production and electromyogram activity during 
ergometer rowing. European Journal of Applied Physiology, 76(6), 495-503. http://doi.org/10.1007/s004210050281

Porter, M. S., Reed, K., \& Jones, B. (2020). The use of acute oxygen supplementation upon muscle tissue saturation during repeat sprint cycling. Journal of Human Sport and Exercise, 17(1). http://doi.org/10.14198/jhse.2022.171.10

Powers, S. K., Martin, D., \& Dodd, S. (1993). Exercise-induced hypoxaemia in elite endurance athletes. Incidence, causes and impact on VO2max. Sports Medicine (Auckland, N.Z.), 16(1), 1422. http://doi.org/10.2165/00007256-199316010-00003

Racinais, S., Bishop, D., Denis, R., Lattier, G., Mendez-Villaneuva, A., \& Perrey, S. (2007). Muscle deoxygenation and neural drive to the muscle during repeated sprint cycling. Medicine and Science in Sports and Exercise, 39(2), 268-274. http://doi.org/10.1249/01.mss.0000251775.46460.cb

Richardson, R. S., Grassi, B., Gavin, T. P., Haseler, L. J., Tagore, K., Roca, J., \& Wagner, P. D. (1999). Evidence of O2 supply-dependentVo 2 max in the exercise-trained human quadriceps. Journal of Applied Physiology, 86(3), 1048-1053. http://doi.org/10.1152/jappl.1999.86.3.1048

Rodriguez, R. F., Townsend, N. E., Aughey, R. J., \& Billaut, F. (2018). Influence of averaging method on muscle deoxygenation interpretation during repeated $\square$ sprint exercise. Scandinavian Journal of Medicine \& Science in Sports, 28(11), 2263-2271. http://doi.org/10.1111/sms.13238

Romer, L. M., Haverkamp, H. C., Amann, M., Lovering, A. T., Pegelow, D. F., \& Dempsey, J. A. (2007). Effect of acute severe hypoxia on peripheral fatigue and endurance capacity in healthy humans. American Journal of Physiology. Regulatory, Integrative and Comparative Physiology, 292(1), R598-R606. http://doi.org/10.1152/ajpregu.00269.2006

Smith, K. J., \& Billaut, F. (2010). Influence of cerebral and muscle oxygenation on repeated-sprint ability. European Journal of Applied Physiology, 109(5), 989-999. http://doi.org/10.1007/s00421-010-1444-4

Smith, K. J., \& Billaut, F. (2012). Tissue Oxygenation in Men and Women During Repeated-Sprint Exercise. International Journal of Sports Physiology and Performance, 7(1), 59-67. http://doi.org/10.1123/ijspp.7.1.59

Sperlich, B., Zinner, C., Krueger, M., Wegrzyk, J., Mester, J., \& Holmberg, H. C. (2011). Ergogenic effect of hyperoxic recovery in elite swimmers performing high $\square$ intensity intervals. Scandinavian Journal of Medicine \& Science in Sports, 21(6), e421-e429. http://doi.org/10.1111/j.1600-0838.2011.01349.x

Szubski, C., Burtscher, M., \& Löscher, W. N. (2006). The effects of short-term hypoxia on motor cortex excitability and neuromuscular activation. Journal of Applied Physiology. http://doi.org/10.1152/japplphysiol.00617.2006

Van Beekvelt, M. C. P., Colier, W. N. J. M., Wevers, R. A., \& Van Engelen, B. G. M. (2001). Performance of near-infrared spectroscopy in measuring local $\mathrm{O} 2$ consumption and blood flow in skeletal muscle. Journal of Applied Physiology, 90(2), 511-519. http://doi.org/10.1152/jappl.2001.90.2.511 
Table 1. Mean changes in performance and perceptual exercise responses in the repeated-sprint ability test in normoxia (NOR,

FIO2: 0.21) or hyperoxia (HYP, FIO2: 0.40).

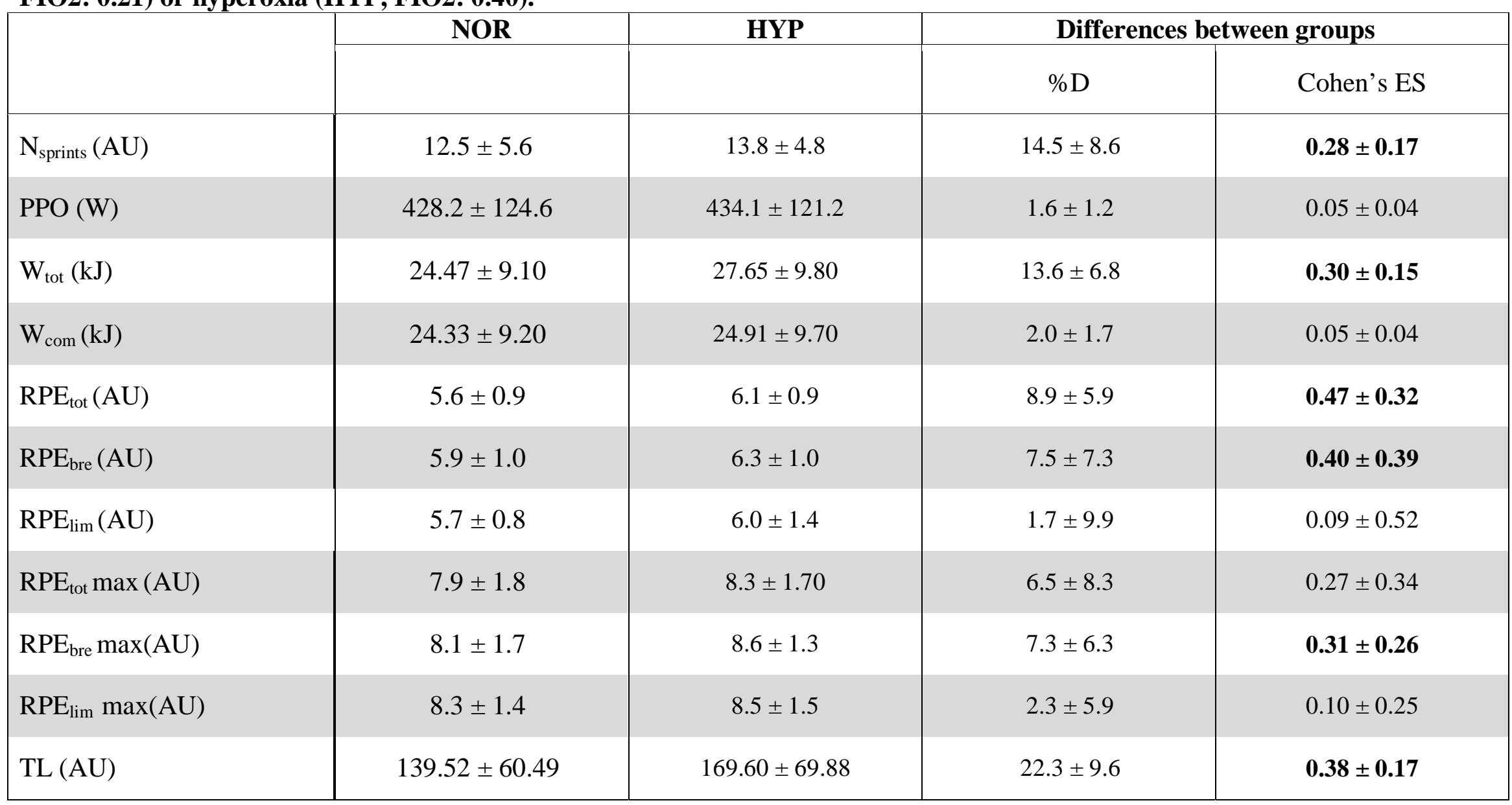

Abbreviations: \%D; percentage difference between changes in NOR and HYP, ES; effect size, Probability \%, percentage chances for HYP to be higher/similar/lower than NOR, $\mathrm{N}_{\text {sprints }}$; number of sprints performed, PPO; peak power outpout, $\mathrm{W}_{\text {tot }}$; total mechanical work of all sprints, $\mathrm{W}_{\text {com }}$; total mechanical work of common sprints, $\mathrm{RPE}_{\text {tot }}$; perceived exhaustion, $\mathrm{RPE}_{\text {lim; }}$ perceived limb discomfort, $\mathrm{RPE}_{\mathrm{bre}}$; perceived difficulty breathing, TL; training load 


\section{$604 \quad 12 \quad$ Legends}

605 Figure 1 Mechanical work performed over the entire series of sprints $\left(\mathbf{W}_{\text {tot }}\right)$ and for the same 606 number of sprints performed in both conditions $\left(\mathbf{W}_{\text {com }}\right)$ session training load over the repeated607 sprint ability test in normoxia and hyperoxia $\left(\mathbf{F}_{\mathbf{I}} \mathbf{O}_{\mathbf{2}} \mathbf{0 . 4 0}\right)$. Data are presented as means $\pm \mathrm{SD}$. * 608 Small effect between conditions. $W_{\text {tot }}$ values were $24.47 \pm 9.1 \mathrm{~kJ}$ in NOR and $27.65 \pm 9.8 \mathrm{~kJ}$ in NYP.

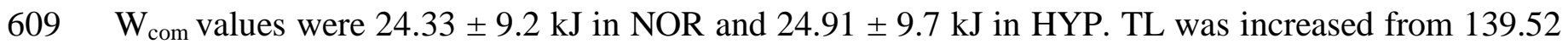
$610 \pm 60.49$ AU in NOR to $169.60 \pm 69.88$ in HYP.

611 Figure 2 Maximal and minimal values of normalized deoxyhemoglobin/myoglobin 612 concentration $([\mathbf{H H b} / \mathrm{Mb}]$, panel $\mathrm{A})$, total hemoglobin/myoglobin concentration $([\mathbf{t H b} / \mathrm{Mb}]$, 613 panel B) and tissue saturation index ([TSI], panel C) over the sprints and recovery periods for 614 the five percentages of test completion in normoxia and hyperoxia $\left(\mathrm{F}_{\mathrm{i}} \mathrm{O}_{2} \mathbf{0 . 4 0}\right)$. Data are 615 presented as means $\pm \mathrm{SD}$, expressed as a percent of the baseline. * Small effect between conditions.

616 Figure 3 Changes for neuromuscular efficiency (NME) over the entire series of sprints $617\left(\mathrm{NME}_{\text {tot }}\right)$ and for the same number of sprints performed in both conditions $\left(\mathrm{NME}_{\text {com }}\right)$ over the 618 repeated-sprint ability test in normoxia and hyperoxia $\left(\mathbf{F}_{\mathbf{I}} \mathbf{O}_{\mathbf{2}} \mathbf{0 . 4 0}\right)$. Data are presented as means \pm 619 SD. * Small effect between conditions. $\mathrm{NME}_{\text {tot }}$ values were 2747.12 \pm 746.54 AU in NOR and $6202975.51 \pm 879.80 \mathrm{AU}$ in $\mathrm{HYP}$. $\mathrm{NME}_{\text {com }}$ values were 2749.86 $\pm 746.07 \mathrm{AU}$ in NOR and $3000.14 \pm$ $621872.70 \mathrm{AU}$ in HYP. 


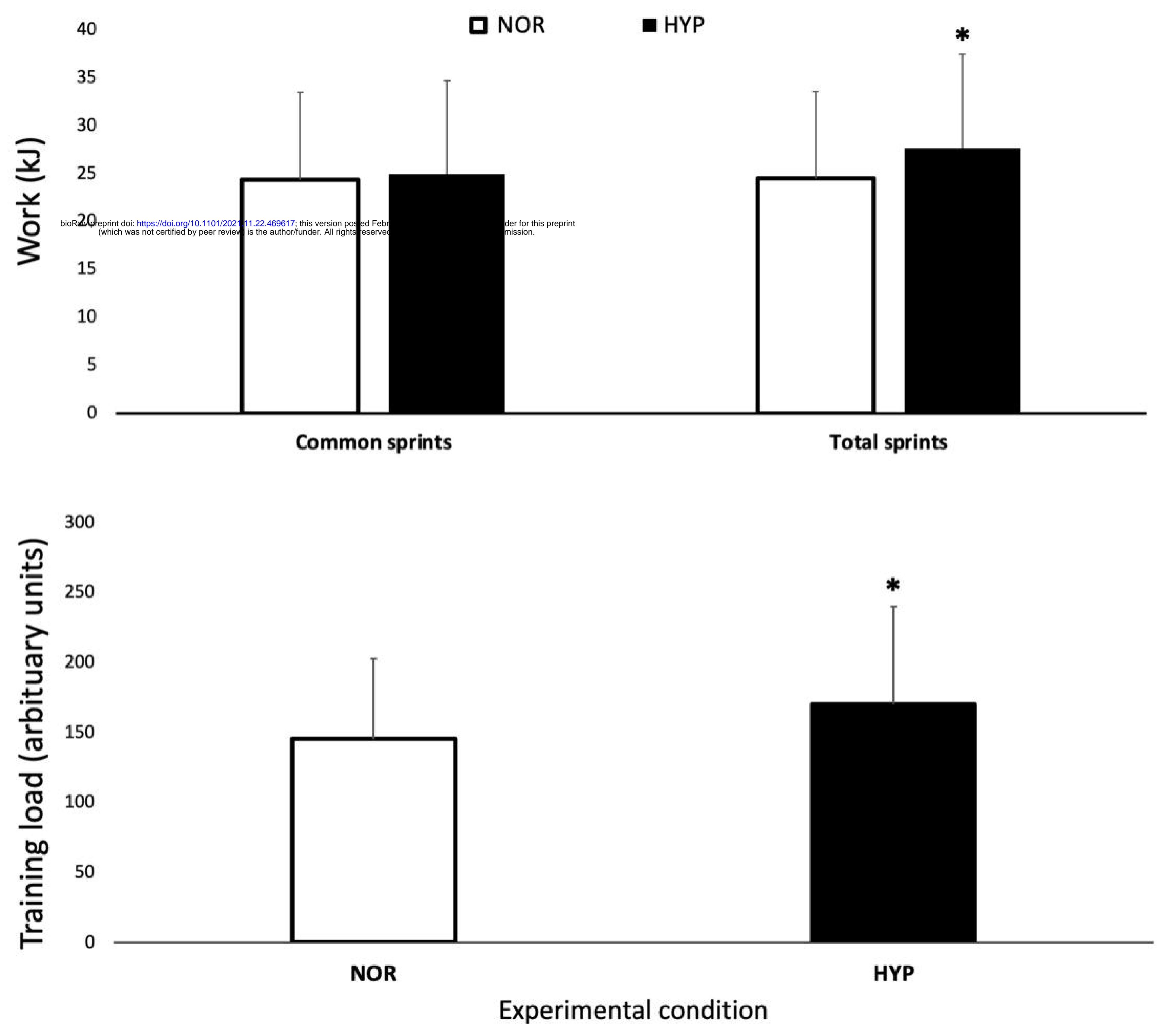


